\title{
DEFINIÇÃO DA DURAÇÃO DA ESTAÇÃO SECA E ESTAÇÃO CHUVOSA E SUA INFLUÊNCIA NA AGRICULTURA NO MUNICÍPIO DE ITUIUTABA - MG
}

\author{
COSTA, Rildo Aparecido - rildocosta@ufu.br \\ Universidade Federal de Uberlândia / UFU
}

\author{
QUEIROZ, Arlei Teodoro - arleiteodoro@yahoo.com.br \\ Instituto Federal de Educação, Ciência e Tecnologia do Triângulo \\ Mineiro / IFTM
}

Submetido em: 09/09/2020

Aceito para publicação em: 04/03/2021

Publicado em: $17 / 04 / 2021$

DOI: http://dx.doi.org/10.5380/abclima.v28i0.76418

\begin{abstract}
RESUMO: Dentre todos os processos que atuam na dinâmica do clima a variabilidade é um dos mais importantes. Suas consequências sejam estas, naturais ou econômicas, afetam sobremaneira a agricultura de uma determinada região. $O$ intuito do desenvolvimento desta pesquisa objetivou determinar o final e o início da estação seca e chuvosa e sua influência na agricultura do município de Ituiutaba, localizado na Mesorregião do Triângulo Mineiro e Alto Paranaíba, mais especificamente na Microrregião de Ituiutaba, no Estado de Minas Gerais. Utilizou-se para isso, dados climáticos obtidos junto à Estação Meteorológica de Ituiutaba, pertencente ao Instituto Nacional de Meteorologia (INMET), utilizando uma série histórica de dados de 30 anos (1988 a 2019). Para definir o excedente e deficiência hídrica, a qual foi essencial para definir o início e final das estações secas e chuvosas, utilizou-se o Balanço Hídrico proposto por Thornthwaite e Mather (1955). A metodologia proposta por Assunção (2012) foi usada para caracterizar o início e final das estações secas e chuvosas para o município de Ituiutaba.Como resultado, notou-se que a média de dias secos por ano foi de 139,1 e observou-seque em $63,4 \%$ dos anos o período seco se iniciou no mês abril, $33,3 \%$ no mês de maio e 3,3\% no mês de março. Em relação ao período chuvoso, em $56,7 \%$ dos anos iniciou em setembro, 33,3\% em outubro e $10 \%$ em agosto. Portanto, há a necessidade de adoção de um calendário agrícola que leve em conta essa dinâmica climática.
\end{abstract}

PAlaVRaS-Chave: Período Seco; Período Chuvoso; Balanço Hídrico; Agricultura

DEFINITION OF THE DURATION OF THE DRY SEASON AND RAINY SEASON AND ITS INFLUENCE ON AGRICULTURE IN THE MUNICIPALITY OF ITUIUTABA - MG

ABSTRACT: Among all the processes that act on climate dynamics, variability is one of the most important. Its consequences, whether natural or economic, greatly affect agriculture in a given region. The purpose of the development of this research was to determine the end and the beginning of the dry and rainy season and its influence on agriculture in the municipality of Ituiutaba, located in the Mesorregião do Triângulo Mineiro and Alto Paranaíba, more specifically in the Microregion of Ituiutaba, in the State of Minas Gerais. For this purpose, climatic data obtained from the Ituiutaba Meteorological Station, belonging to the National Meteorological Institute (INMET), were used, using a 30-year historical data series (1988 to 2019). To define the water surplus and deficiency, which was essential to define the beginning and end of the dry and rainy seasons, the Water Balance proposed by Thornthwaite and Mather (1955) was used. The methodology proposed by Assunção (2012) was used to characterize the beginning and end of the dry and rainy seasons for the municipality of Ituiutaba. As a result, it was noted that the average dry day per year was 139.1 and that it was observed that in $63.4 \%$ of the years the dry period started in April, 33.3\% in May and 3.3\% in month March. In relation to the rainy season, in $56.7 \%$ of the years started in September, 
$33.3 \%$ in October and $10 \%$ in August. Therefore, there is a need to adopt an agricultural calendar that takes into account this climate dynamic.

KEYWORDS: Dry Period; Rainy Period; Hydric balance; Agriculture

\section{INTRODUÇÃO}

Dentro da dinâmica climática a variabilidade é dos elementos mais conhecidos e estudados nos dias atuais. O impacto produzido por essa variabilidade, mesmo dentro do esperado, pode ter reflexos significativos em todas as atividades humanas, podendo até mesmo desestruturar os sistemas ambientais e econômicos (QUEIROZ; COSTA, 2012).

A inquietação em relação às consequências dessa variabilidade climática na agricultura é pauta de discussões científicas, bem como em toda a esfera social na atualidade (MAIA; SANTOS, 2003; DINIZ, 2016), devido principalmente ao processo de uso e ocupação do espaço rural, onde as transformações no meio físico são notórias, gerando vários impactos ambientais em função do grau de magnitude da ocupação.

Portanto, destaca-se aqui a importância dos estudos climáticos, em suas diversas escalas, como fundamentais para se compreender as influências dos elementos climáticos e sua variabilidade no processo de organização espacial no meio rural.

O comportamento do clima afeta sobremaneira todos os estágios da produção agrícola, desde a preparação do solo para o início do cultivo até a colheita, evidenciando assim, o clima como o fator mais importante do desenvolvimento da agricultura e pecuária.

Para Brunini et al. (1983), a variabilidade dos elementos climáticos em suas diversas escalas temporo-espaciais é essencial como conhecimento para cada estágio de desenvolvimento dos cultivares, além do seu armazenamento e transporte. Fornecendo assim uma série de dados científicos no intuito de beneficiar a produção agrícola, ou seja, "quanto mais importante economicamente é um vegetal, maior será a necessidade de se conhecer suas características climáticas e as possíveis variações que sofre ao se desenvolver em condições climáticas que não satisfaçam plenamente suas exigências" BRUNINI et al. (1983, p. 23).

Os principais elementos climáticos que influenciam na produção agrícola são a radiação solar, temperatura e umidade, sendo que a umidade, em todas as suas formas (precipitação, umidade do solo e umidade do ar), se destacam como a mais importante no crescimento e desenvolvimento dos cultivares (AYOADE, 2003).

O estudo das estações chuvosas e secas são, sem dúvida, significativos no processo de organização do espaço geográfico, principalmente nas áreas rurais.A quantidade e distribuição (espacial e temporal) de chuvas que ocorrem em uma determinada região, são responsáveis pela vegetação natural e a exploração agrícola que será possível de se praticar. Portanto, o ritmo anual das precipitações permite a "escolha das melhores épocas de semeadura, visando a ajustar o ciclo das culturas anuais às melhores condições locais do clima" PEREIRA et al. (2002, p. 13).

Neste contexto, avaliar novas metodologias que consiga determinar 0 início da estação chuvosa e o início da estação seca é de fundamental 
importância, para vislumbrar um planejamento mais profícuo das atividades ligadas ao desenvolvimento agrícola tais como: calendário agrícola das culturas, escolhas dos cultivares, manejo da irrigação, $2^{a}$ safra de verão e colheita.

Schneider e Silva (2014) utilizou o método estatístico Box Plot para caracterização e identificação de anos padrão secos, chuvosos e habituais para a Microrregião de Dourados, no Estado de Mato Grosso do Sul. Foram analisados 396 meses, sendo que, 25 meses se apresentaram super-secos; 85 meses secos; 126 meses habituais; 81 meses chuvosos e 79 meses super-chuvosos. 0 método utilizado foi considerado relevante, pelos autores, na contribuição da identificação de estudos e pesquisas com objetivo de se compreender as ocorrências de anos padrão. Se mostrou uma ótima ferramenta estatística no âmbito da climatologia geográfica.

Em seus estudos Machado et. al. (1996) utilizando-se de dados diários de precipitação para caracterizar a estação chuvosa para o estado de Minas Gerais. Evidenciaram que, quando a estação chuvosa se iniciou precocemente houve uma diminuição temporal nestas precipitações e, quando esta estação chuvosa começou tardiamente houve uma expansão dos dias de chuva.

Roldão e Assunção (2012), definiram a duração das estações seca e chuvosa para o Triângulo Mineiro, utilizando dados de precipitação de quatro estações meteorológicas pertencentes a Agencia Nacional das águas (ANA), sendo uma série de 30 anos. O Balanço Hídrico serviu como auxilio para os estudos. Foi verificado uma média de $1490 \mathrm{~mm}$ de pluviosidade anual, com uma duração média de 175 dias da estação seca (abril a setembro/outubro) e 190 dias da estação chuvosa (setembro/outubro a abril).

Em seu estudo de caracterização da precipitação para o estado do Paraná, Nery et. Al. (1996) utilizaram o Método de Análise de Fourier e a Análise Multivariada para definir os períodos mais chuvosos e períodos mais secos em cada região do Estado. Foi apontado que o Estado possui dois períodos distintos: enquanto nas regiões leste, sudeste e nordeste houve uma concentração no verão, nas regiões central e oeste uma precipitação mais uniforme, durante o ano.

Conhecer o comportamento espacial e temporal da precipitação (estação seca e estação chuvosa) é essencial para um planejamento mais eficaz e assertivo, visando estratégias para a redução de impactos negativos na sociedade e influenciando na tomada de decisões, principalmente na agricultura. Nas áreas rurais o conhecimento das chuvas proporciona um entendimento melhor das atividades agrícolas, buscando reduzir perdas e melhorar as condições de produção.

Definir e caracterizar o período seco e chuvoso de uma determinada região não é tarefa fácil, principalmente quando se trata do domínio do Cerrado, pois, apesar de possuir as duas estações bem definidas, em uma escala global, na escala regional isso se torna mais complexo, devido a variabilidade pluviométrica.

A proposta da presente pesquisa é determinar a duração da estação seca e estação chuvosa no município de Ituiutaba - MG, além de se destacar sua influência na agricultura. Tal estudo se justifica em função da importância econômica que o município representa para o Pontal do Triângulo Mineiro, 
ligados diretamente ao setor agropecuário e sua conexão direta com a dinâmica climática.

\section{CARACTERIZAÇÃo DA ÁREA DE ESTUDO}

A área de estudo, município de Ituiutaba, situado no Triângulo Mineiro, a oeste no Estado de Minas Gerais, localizado na mesorregião do Triângulo Mineiro e Alto Paranaíba, mais especificamente na microrregião de Ituiutaba, delimitado pelas coordenadas geográficas 49052'W/ 49010'W e 18036S/ 190,21'S (Figura 1). Possui uma área de $2.587 \mathrm{Km}^{2}$. Geograficamente o município está distante 696 km da capital mineira Belo Horizonte.

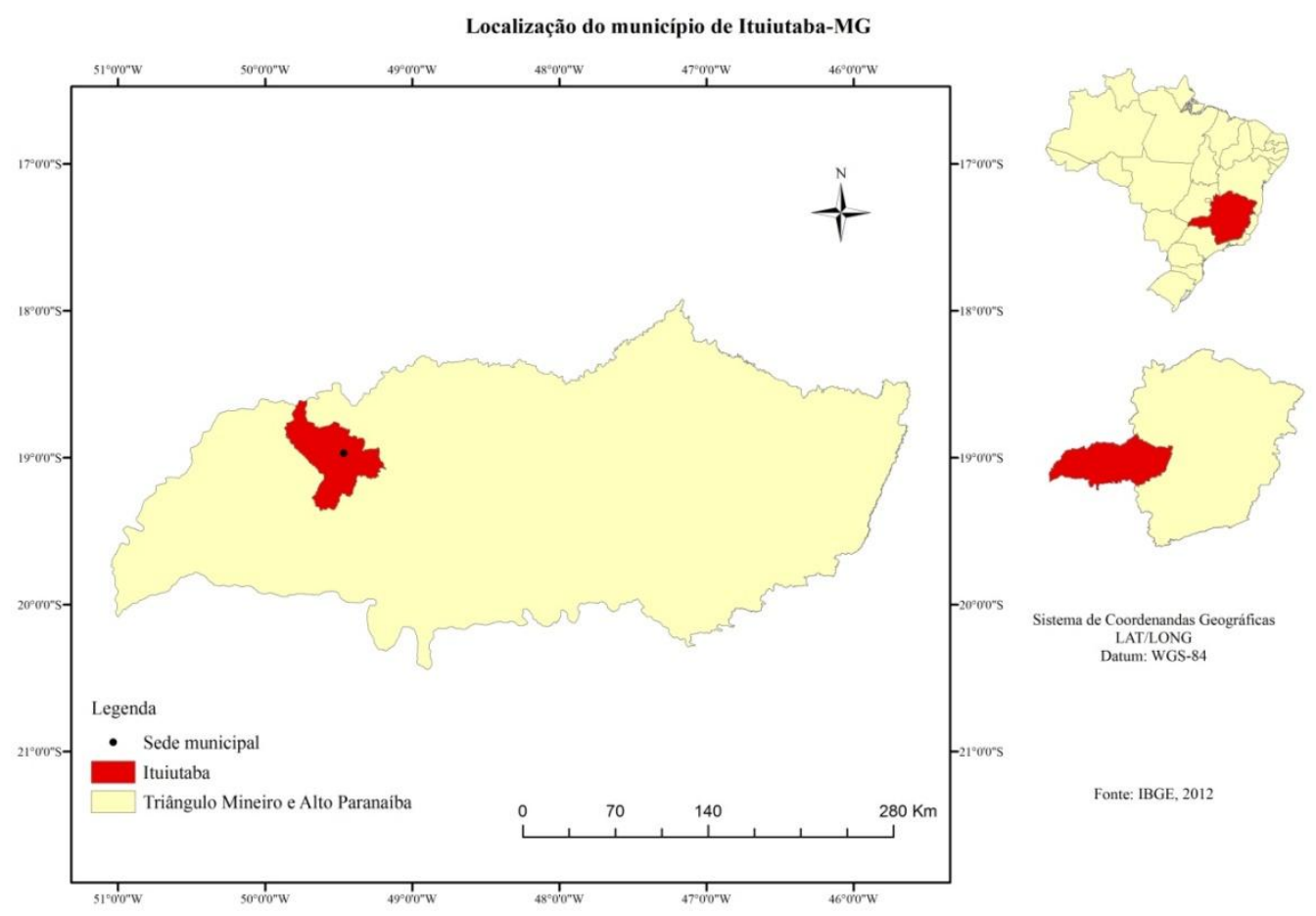

Figura 1 - Ituiutaba-MG: Localização do município. Fonte: IBGE, 2012.

O município possui, em quase todo o seu território, o Cerrado como bioma predominante, embora grande parte desta área já foi substituída pela agricultura e pecuária, restando somente áreas de Preservação Permanente, declividades mais altas e Reservas Legais. É comum encontrar, nas áreas mais baixas as veredas, que são caracterizadas por solos mal drenados e o acúmulo de águas, formando as nascentes das áreas de Cerrado. Nas partes mais altas, em solos mais desenvolvidos encontra-se o Cerradão que devido ao avanço agropecuário foi quase todo desmatado. (COSTA, 2011)

Está localizado na Bacia Sedimentar do Paraná, mais precisamente nos domínios de chapadas e chapadões do Triângulo Mineiro, que tem como principal característica relevos suavemente ondulados, com vales pouco desenvolvidos (BACCARO, 1991). Se destacando os topos de chapadas, onde se desenvolve a agricultura atualmente. Nas bordas das chapadas se destaca a pecuária extensiva. 
Os principais tipos de solo que ocorrem em Ituiutaba pertencem à classe dos Latossolos, com destaque para o Latossolo Vermelho Amarelo, Vermelho Escuro e o Roxo, sendo este último associado a áreas de ocorrência de rochas magmáticas no município. Porém a maior parte do município é coberto por solos de origem arenítica (Formação Marília), geralmente solos bem desenvolvidos. Embora estes solos não sejam férteis (naturalmente), a forma suave do relevo favorece o desenvolvimento da agricultura.

Essa região está sob a influência, de forma geral, da dinâmica de Massas de $\operatorname{Ar}$ Polar, que é responsável pela entrada de frentes frias e da Massa Equatorial Continental, responsável pela distribuição da umidade na região. 0 verão é caracterizado por sucessões de dias com temperaturas elevadas que tem a influência da massa tropical atlântica continentalizada (mTac), e dias com temperaturas amenas (inverno) causado pela ação da massa polar atlântica $(\mathrm{mPa})$. Há também significativa escassez de umidade e precipitação no inverno. Desta forma, o município de Ituiutaba apresenta o clima tropical com duas estações bem definidas, o verão chuvoso e com temperaturas elevadas e o inverno com escassez de chuvas e temperaturas amenas. (MENDES; QUEIROZ, 2011, p. 336).

Também é comum a ocorrência da ZCAS (Zona de Convergência do Atlântico Sul), que se estende da porção sul da região Amazônica ao litoral da Região Sudeste, passando sobre o Triângulo Mineiro, provocando nebulosidade e chuvas intensas por dias e até semanas. Nos meses de inverno ocorre a atuação de dois sistemas principais: mTac, responsável por dias de temperaturas elevadas e baixa umidade relativa do ar, e a $\mathrm{mPa}$ com temperaturas amenas. As estações de primavera e outono são consideradas de transição seca/chuvosa e chuvosa/seca, respectivamente. (MENDES; QUEIROZ, 2011).

Em 2018, de acordo com o IBGE, o munícipio de Ituiutaba possuía em torno de $25 \%$ de área ocupada pela agricultura contribuindo de forma direta, com 5\% do produto interno bruto (PIB) municipal, sendo que as lavouras temporárias de cana-de-açúcar, milho, soja e sorgo são as apresentam representatividade em área de plantio (Gráfico 1). Cabe destacar aqui que, embora possa parecer baixo o PIB vindo da agricultura, ela movimenta boa parte do setor terciário do município.

Apesar dos quatro principais cultivos serem considerados lavouras temporárias, a cana-de-açúcar possui um ciclo de colheita muitas vezes superior a 12 meses, ou seja, a planta tem capacidade de suportar o período chuvoso e seco característico da região sem irrigação. 


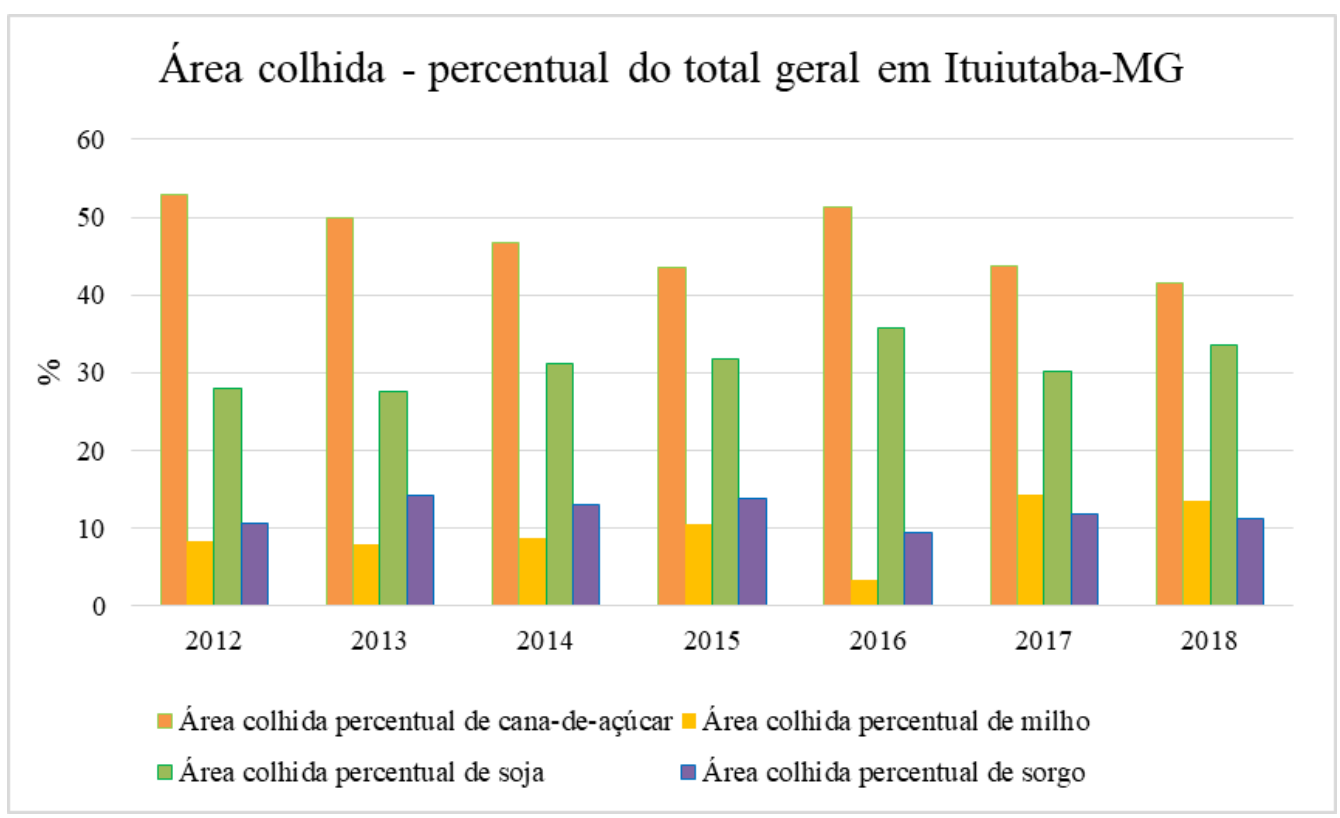

Gráfico 1 - Ituiutaba-MG: Área colhida - percentual dos principais cultivos no total geral. Fonte de dados: IBGE, 2020. Org: Costa e Queiroz, 2020

A soja, o milho e o sorgo são culturas que necessitam de água (neste caso, principalmente por precipitação para incorporação ao solo) em diversas etapas do seu desenvolvimento. Dessa forma, a produção destas lavouras, estão vinculadas ao período chuvoso na região. Sendo que, tendo em vista o avanço tecnológico, o tempo necessário para o cultivo destas plantas reduziu o que possibilitou a execução de duas safras no período chuvoso, no entanto, a produtividade das mesmas está intrinsicamente ligada extensão e dinâmica do período chuvoso.

Diante do exposto, vale destacar que quando se faz duas safras, normalmente o plantio da soja ocorre na primeira safra, dentre os fatores que influenciam tal ação é o fato de que, conforme normatização do Instituto Mineiro de Agropecuária (IMA), no período de $1^{0}$ de julho a 15 de setembro ser considerado vazio sanitário da soja no estado de Minas Gerais, quando é proibido manter nas lavouras plantas vivas de soja.

No Gráfico 2, é possível observar, também, as diferenças de produtividade (toneladas por hectare) na primeira e segunda safra de milho, sendo que, conforme já relatado, uma das principais variáveis que pode contribuir para a produtividade maior está relacionado extensão e dinâmica do período chuvoso. Ou seja, o atraso do início do período chuvoso pode prejudicar a primeira safra e o início precoce do período seco pode comprometer os resultados da segunda safra. 


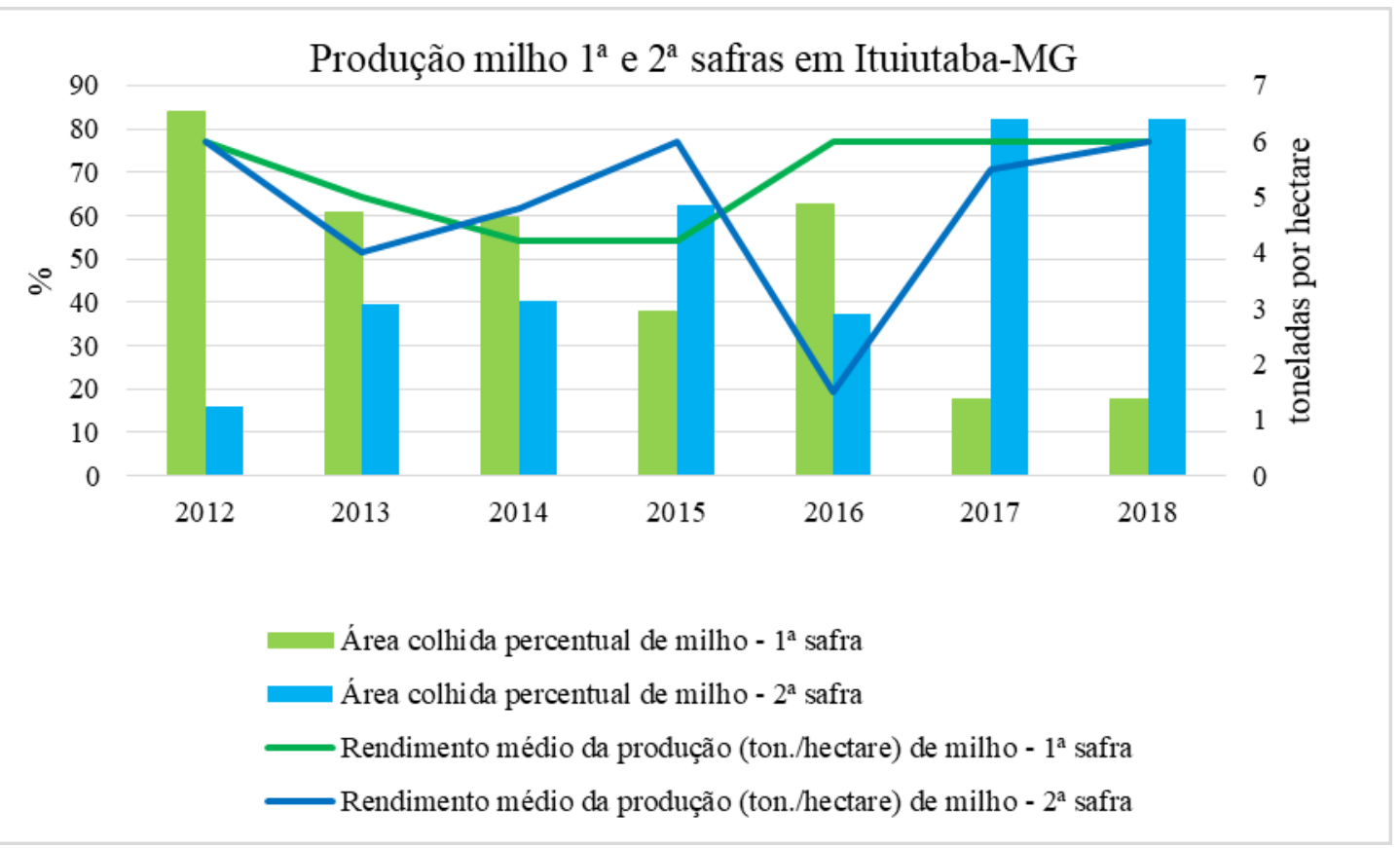

Gráfico 2 - Ituiutaba-MG: Produção e área colhida de milho nas $1^{\text {a }}$ e $2^{\mathrm{a}}$ safras. Fonte de dados: IBGE, 2020. Org: Costa e Queiroz, 2020

A cultura do milho se destaca por ter seu ciclo de cultivo tanto na primeira como na segunda safra (Gráfico 2), sendo que nos últimos anos (2017 e 2018) a área colhida de milho na segunda safra foi mais de $80 \%$ do total da área destinada a produção de milho.

\section{METODOLOGIA}

Compreender o início e o final da estação seca e chuvosa é complexo, principalmente para as áreas do Cerrado brasileiro, devido à grande variabilidade pluviométrica que é o resultado das ações das massas de ar que afetam a região, além do próprio relevo regional.

Para se compreender o início e o fim das estações seca e chuvosa, existente no município de Ituiutaba optou-se por trabalhar com uma série históricade precipitação, sendo que para realização deste trabalho foram utilizados dados do período de 1988 a agosto de 2019, da Estação Meteorológica de Ituiutaba, localizada na latitude $18^{\circ} 57^{\prime} 10^{\prime \prime} \mathrm{S}$ e longitude $49^{\circ} 31^{\prime} 31^{\prime \prime} \mathrm{W}$ e com uma altitude de 560 metros, distante aproximadamente $5 \mathrm{Km}$ da sede do município de Ituiutaba. Os dados de precipitação foram disponibilizados pelo Instituto Nacional de Meteorologia (INMET), através de seu site, sendo que o INMET é órgão responsável pela manutenção da estação.

A tabulação dos dados e a elaboração de gráficos foram feitas utilizando o software Microsoft Office Excel. Sobre a utilização de gráficos, Ayoade (2003, p.241) afirma que "o clima de uma região é descrito com a ajuda de gráficos das variações sazonais nos valores dos elementos climáticos, usualmente a temperatura e a precipitação". 
Ainda utilizando este software, foi possível calcular e plotar a linha de tendência linear simples dos dados. Sobre a linha de tendência/regressão linear simples, Naghettini e Pinto descrevem o método da seguinte forma:

Muitas vezes, a simples visualização do diagrama de dispersão sugere a existência de uma relação funcional entre as duas variáveis. Essa observação introduz o problema de se determinar uma função que exprima esse relacionamento. A análise de regressão é uma técnica estatística cujo escopo é investigar e modelar a relação entre variáveis.

Considerando que exista um relacionamento funcional entre os valores $Y$ e $X$, responsável pelo aspecto do diagrama, essa função deverá explicar parcela significativa da variação de $Y$ com $X$. (...) Frequentemente, os pontos observados apresentarão uma variação em torno da linha da função de regressão, devido à existência de uma variação aleatória adicional denominada de variação residual. Portanto, essa equação de regressão fornece o valor médio de uma das variáveis em função da outra. (NAGHETTINI; PINTO, 2007, p. 362)

Ainda sobre os dados utilizados, vale salientar que, por motivo desconhecido, em alguns momentos não foram feitas a coleta e anotação dos dados, desta forma, em alguns casos devido a estas ausências, os dados foram desconsiderados. Sendo assim, mesmo com tais problemas, optou-se por utilizar esta série de dados neste estudo de variabilidade climática ainda que seus resultados devam ser vistos com ressalvas, pois são as únicas fontes que se tem.

Aliando-se os dados de precipitação com os de temperatura do ar, tornou-se possível realizar o cálculo do Balanço Hídrico para todos os anos compreendidos no estudo da localidade de análise. Na construção do Balanço Hídrico Mensal foi utilizada a metodologia proposta por Thornthwaite e Mather (1955), considerando-se como padrão uma capacidade de campo (CAD) de 100 $\mathrm{mm}$.

Para facilitar a elaboração dos cálculos do balanço, utilizou-se ainda, um software desenvolvido por Rolim e Sentelhas (2000) do Departamento de Ciências Exatas - Área Física e Meteorológica da ESALQ/USP. O Balanço Hídrico foi importante para a definição dos meses secos e úmidos, servindo também para a definição da Evapotranspiração Potencial (ETP) diária a qual foi calculada dividindo o valor mensal pelo total de dias de cada mês.

Assim, em função da ETP diária estabeleceu como dias com chuvas insignificantes aqueles em que a precipitação diária acumulada é inferior a esse total, de forma que as chuvas acumuladas não são suficientes para interromper o período de estiagem ou que não tem relevância do ponto de vista agronômico.

Utilizou-se como metodologia para se chegar ao objetivo do trabalho as denominadas dez leis básicas para determinação da duração das estações seca e chuvosa desenvolvidas por Assunção (2012):

1 - Período chuvoso significa o fim do incremento do déficit hídrico no solo, o qual passa a ser reabastecido pelos excedentes hídricos (chuvas maiores que a ETP) e, à medida que os dias vão passando, o nível de água acumulado no solo atinge a capacidade de campo e a partir de então começa o registro de excedentes hídricos, importantes na manutenção de um complexo sistema fluvial na região responsável pelo grande potencial hidroelétrico regional. 
2 - Os meses de dezembro, janeiro e fevereiro são todos considerados do período chuvoso. Quando houver o registro de déficit hídrico mensal este fato deve ser associado ao registro de um veranico (intervalo sem precipitações dentro da estação chuvosa) de média a forte intensidade.

3 - Os meses de junho, julho e agosto são todos considerados do período seco. Caso ocorra o registro de excedentes hídricos em qualquer um desses meses este fato pode ser associado ao fenômeno conhecido localmente como "invernico" (ocorrência de chuvas mais intensas dentro da estação seca geralmente de origem frontal).

4 - O período chuvoso tem início quando se verifica a ocorrência de uma chuva mais intensa (acima de $20 \mathrm{~mm}$ ) ou um acumulado de $40 \mathrm{~mm}$ em um curto período de dias (até 4 dias) e em seguida, as chuvas passam a ser mais frequentes e suficientes para repor a ETP acumulada e iniciar a reposição de água no solo.

5 - Se houver chuvas bem distribuídas em setembro, não significa que este mês seja chuvoso. É preciso verificar se as precipitações em outubro (se houve uma interrupção ou um período superior a 12 dias sem chuva) foram suficientes para repor a ETP do mês ou se houve déficit hídrico.

6 - Quando o mês de outubro se apresentar úmido (com chuva igual ou superior a ETP mensal e bem distribuída) e em novembro verificar uma redução nos totais pluviométricos acumulados (porém superior a $60 \%$ da ETP mensal) a conclusão é de que a estação chuvosa teve seu início em outubro. Porém se observar nos primeiros dias de novembro uma grande sequência de dias sem precipitações (acima de 12 dias), a estação chuvosa só começa após o reinício das chuvas depois desse período de interrupção.

7 - O fim do período chuvoso (ou o início da estação seca) fica caracterizado após uma sequência de 8 ou mais dias consecutivos sem ocorrência de precipitações ou com precipitações muito baixas nesse período e que nem atingem a metade da ETP diária. Após esse período as precipitações quando houver já não são tão frequentes e acima de tudo não são suficientes para repor os níveis de água no solo.

8 - Se no mês de março ocorrer totais pluviométricos acumulados abaixo da ETP mensal e no mês de abril os acumulados ficarem acima de $80 \%$ da ETP mensal e com chuvas bem distribuídas ao longo do mês o que se observa é que as baixas precipitações em março devem-se a ocorrência do fenômeno veranico.

9 - O mês de maio só é considerado úmido se em abril as chuvas forem abundantes e suficientes para repor a ETP mensal. Caso isso não ocorra, as chuvas mesmo abundantes no mês de maio passam a ser consideradas como chuvas isoladas.

10 - Para efeito de análise considerou no presente trabalho, o início da estação seca, no dia imediatamente após a última chuva antes de uma sequência de 8 ou mais dias sem registro de chuvas ou com precipitações insignificantes (cujos acumulados diários geralmente fica abaixo da metade da ETP). Vale lembrar que como o solo está com o nível de água elevada os efeitos da estação seca como o "murchamento" e a cessão do crescimento vegetativo das culturas só se faz perceber após passar um período de alguns dias (8 a 10), sendo afetado em maior ou menor prazo em função da temperatura ambiente. 


\section{RESULTADOS E DISCUSSÕES}

A sazonalidade climática é a característica mais marcante nos climas do cerrado brasileiro, proporcionando duas estações bem definidas, estação seca (abril a outubro) e estação chuvosa (novembro a março). Como pode ser observado, de forma geral, no gráfico 3. Essa sazonalidade é determinante para a paisagem do cerrado do Brasil Central, além de condicionar também as atividades humanas (sociais e econômicas), onde se destaca a agricultura.

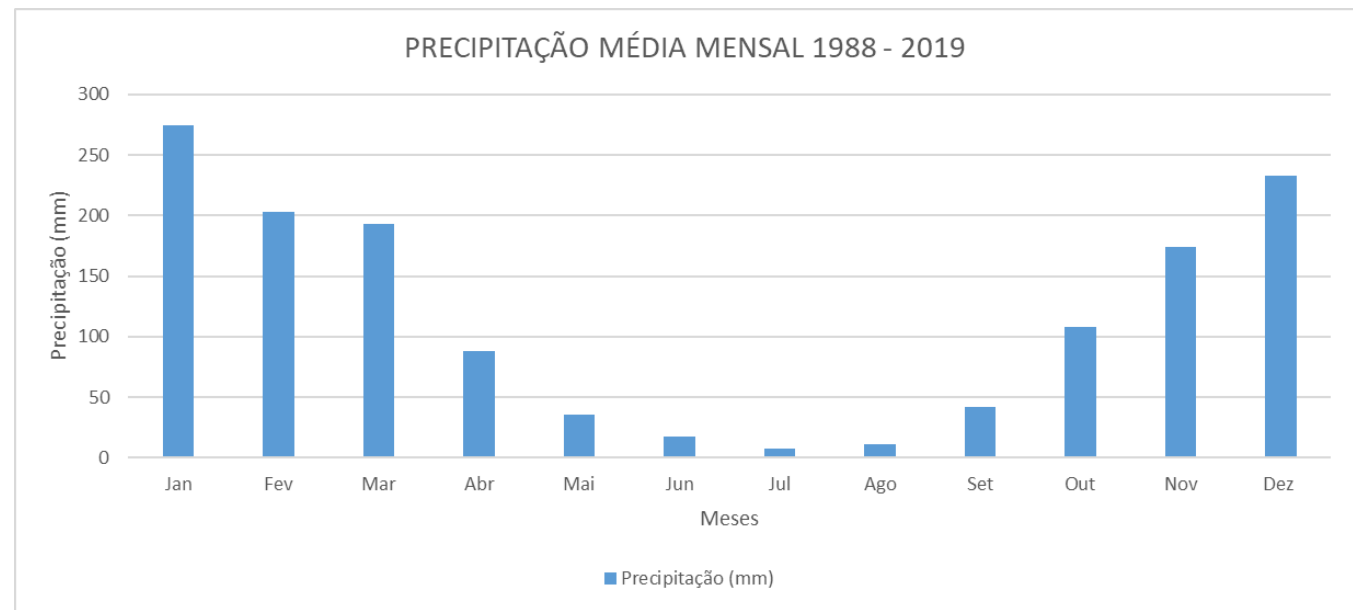

Gráfico 3 - Ituiutaba-MG: Precipitação Média Mensal 1988 - 2019. Fonte de dados: Instituto Nacional de Meteorologia - INMET. Org: Costa e Queiroz, 2020.

Em relação a sazonalidade climática na área de estudo, pode evidenciar que a média da precipitação para o município é de $1.387,3 \mathrm{~mm}$ anuais, sendo que o período chuvoso (outubro a março) corresponde a aproximadamente $82 \%$ das chuvas anuais. O trimestre de dezembro a fevereiro, possui uma concentração de precipitação, sendo responsável por aproximadamente $51 \%$ do total anual para o município de Ituiutaba. O trimestre mais seco (junho a agosto) representa apenas 2,6\% do total de precipitação (Quadro 1).

Quadro 1 - Extrato das Informações do Balanço Hídrico Médio (1988 - 2019)

\begin{tabular}{|c|c|c|c|c|c|c|c|c|c|c|c|c|c|}
\hline Variáveis & Jan & $\mathrm{Fev}$ & Mar & $\mathrm{Abr}$ & Mai & Jun & Jul & Ago & Set & Out & Nov & Dez & Total \\
\hline Média da Precipitação & 274,3 & 202,7 & 193,2 & 88,1 & 35,3 & 17,6 & 7,5 & 11,2 & 41,8 & 108,2 & 174 & 233,3 & $1.387,30$ \\
\hline ETP & 109,2 & 101,1 & 113,7 & 101,7 & 81,1 & 67,5 & 74,7 & 96,1 & 121,7 & 133,2 & 111,1 & 111 & 1222,2 \\
\hline Déficit & 0 & 0 & 0 & 1,3 & 14,9 & 28,9 & 51,3 & 75,1 & 75,6 & 23,9 & 0 & 0 & 271,09 \\
\hline Probabilidade de DEF (\%) & 0 & 0 & 0 & 48 & 78 & 92 & 97 & 98 & 77 & 43 & 4 & 0 & \\
\hline Excedente & 170,8 & 91,9 & 76 & 0 & 0 & 0 & 0 & 0 & 0 & 0 & 0 & 86,8 & 425,5 \\
\hline Probabilidade de EXC (\%) & 97 & 85 & 79 & 41 & 11 & 2 & 0 & 0 & 0 & 13 & 52 & 97 & \\
\hline
\end{tabular}

Fonte: Instituto Nacional de Meteorologia e Dados do Balanço Hídrico de Thornthwaite \& Mather (1955)

Outro aspecto descrito na literatura e que pode ser observado no Quadro 1 é que a Evapotranspiração Potencial do município é maior durante os meses mais quentes do ano, ou seja, os meses em que há maior entrada de energia no sistema através da radiação solar. Coincidentemente, neste mesmo período são registrados os meses com maior precipitação. Com essa recarga de água durante este período reduz significativamente a necessidade de se aplicar a irrigação na lavoura. 
Durante a estação seca podemos notar que a ETP é menor, tendo seus menores índices registrados nos meses de junho e julho, período que se destaca com a ocorrência das menores temperaturas do município. É justamente neste período que as águas superficiais e subterrâneas do município são utilizadas pela agricultura. Essa irrigação é essencial para a manutenção e desenvolvimento da agricultura local.Os valores médios dos déficits hídricos (DEF) são maiores nos meses de junho a setembro, representando aproximadamente $85 \%$ dos déficits hídricos anuais. Nestes mesmos meses há uma alta probabilidade de ocorrência de déficit, sendo um fator de suma importância para se considerar na análise da estação seca.

Os excedentes hídricos (EXC) anuais são observados no período de dezembro a março, estes meses possuem uma maior probabilidade de se ter EXC nos solos, principalmente nos meses de dezembro, janeiro e fevereiro, que são responsáveis por boa parte das precipitações do município de Ituiutaba.

Em Ituiutaba, tem-se uma variabilidade nos dias sem chuva (gráfico 4), porém observa-se que o ano de 1994 (177 dias sem chuva), 2002 (167 dias sem chuva) e 2010 (167 dias sem chuva) se destacam na série de dados utilizadas, embora não representam as menores precipitações anuais, o que reforça a importância de compreender a distribuição temporo-espacial e a intensidade das precipitações no munícipio.

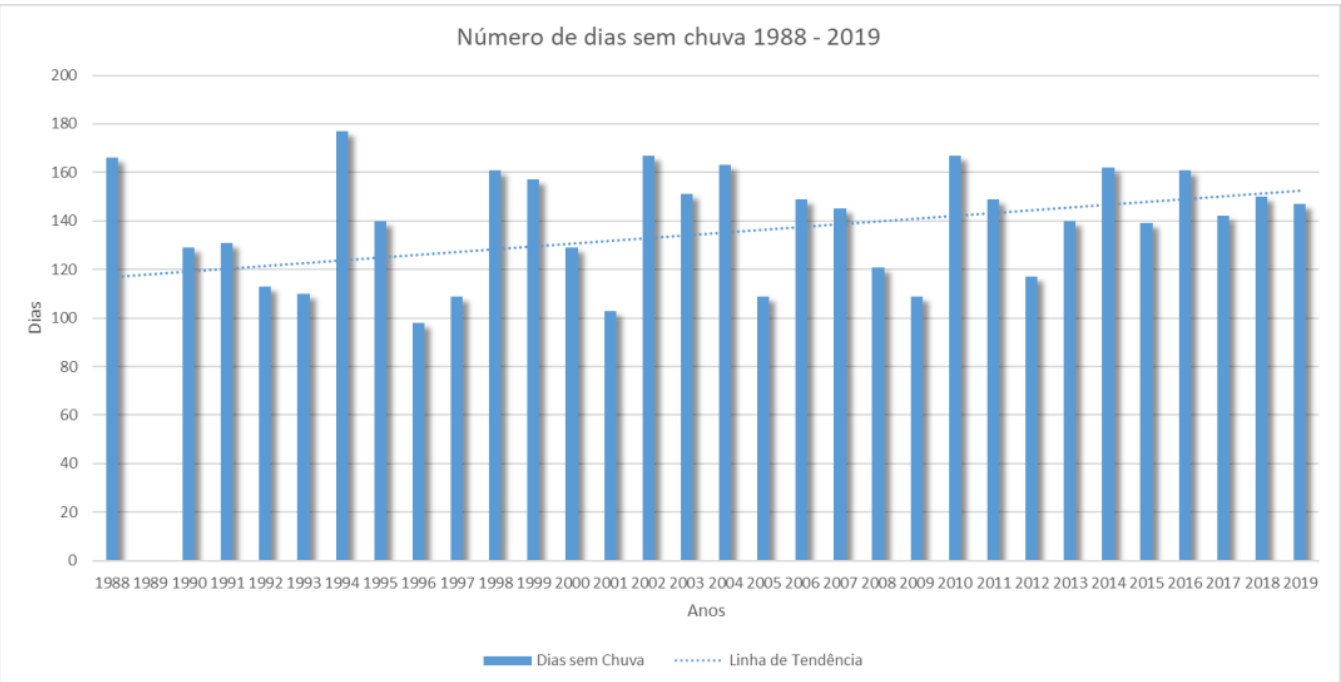

Gráfico 4 - Ituiutaba - MG: Número de Dias Sem Chuva. Fonte de dados: Instituto Nacional de Meteorologia - INMET. Org: Costa e Queiroz, $2020 *$ O ano de 1989 não possui dados

Quando se traça uma linha de tendência, fica evidente o aumento dos dias sem chuva, a cada dez anos tem-se o aumento de aproximadamente $6,5 \%$ nos dias sem chuva, indicando que estes dias possuem uma tendência de crescimento.

Em relação à média de precipitação anual (gráfico 5) observa-se que o ano de 2008 (1703,4 mm), com apenas 121 dias sem chuva e 2009 (1620,8 $\mathrm{mm}$ ), com 109 dias sem chuva,foram os anos mais chuvosos da série estudada. Os anos de 2015 (1030,2 mm), com 161 dias sem chuva e 2018 (985,6 mm), com 150 dias sem chuva, foram os anos mais secos. 


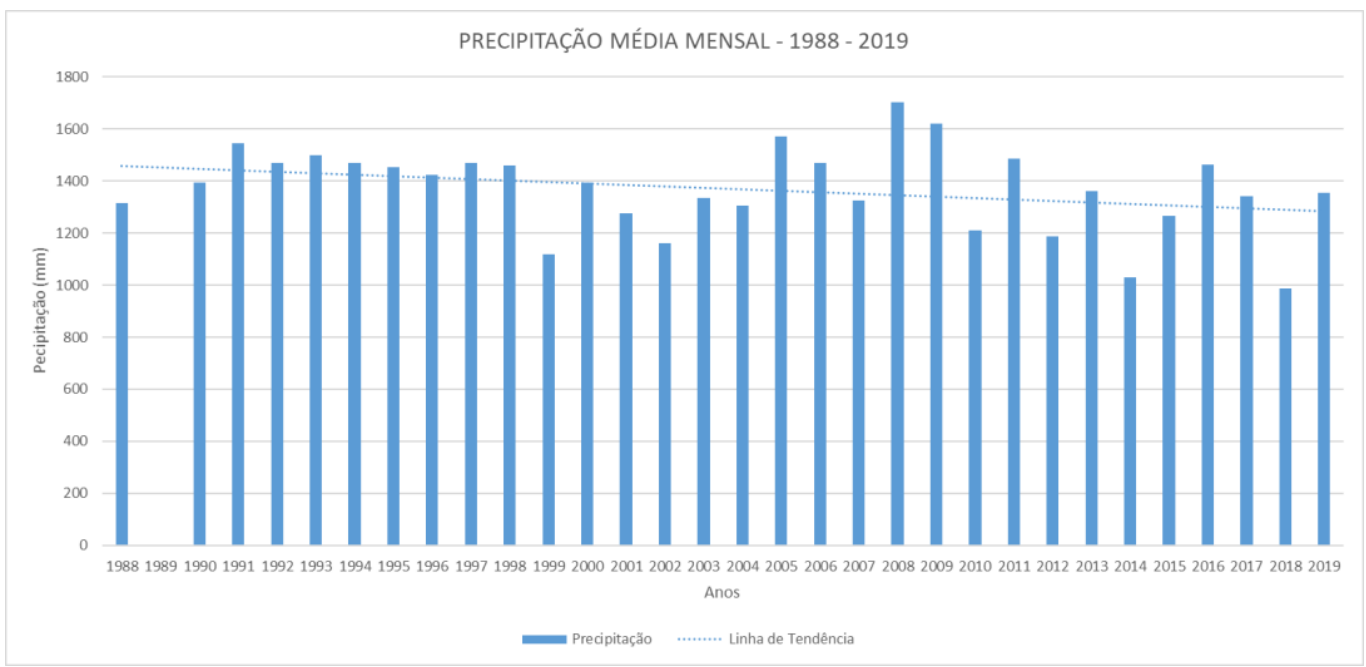

Gráfico 5 - Ituiutaba - MG: Precipitação Média Anual. Fonte de dados: Instituto Nacional de Meteorologia - INMET. Org: Costa e Queiroz, 2020. * O ano de 1989 não possui dados

Quando se observa a linha de tendência é notório a queda na precipitação médiaanual nos dados estudados. A partir de 2005 se tem uma variação na média da precipitação mensal significativa.

Observando o gráfico 6 nota-se que a estação seca tem uma média de 139,1 dias para o município de Ituiutaba, embora, entre os anos analisados registrou-se uma grande variação na duração da mesma. O ano de 1986 se destacou com o menor período de duração da estação seca para toda a série estudada. O ano de 1994 se destacou como a mais longa estação seca, com 177 dias de estiagem.

$\mathrm{Na}$ série histórica trabalhada nesse artigo, (1988 a 2019) aproximadamente $53 \%$ da estação seca se iniciou no mês de abril. Essa observação é de suma importância para a agricultura, haja vista que afeta a produtividade, poisas precipitações possibilitam o processo de crescimento e enchimento de grãos nas lavouras no final de abril e início de maio e, posteriormente, no período seco ocorreria a maturação e colheita. Neste sentido, a extensão da estação chuvosa até abril contribui para a produtividade da $2^{\mathrm{a}}$ safra, conhecida na região como safrinha. 


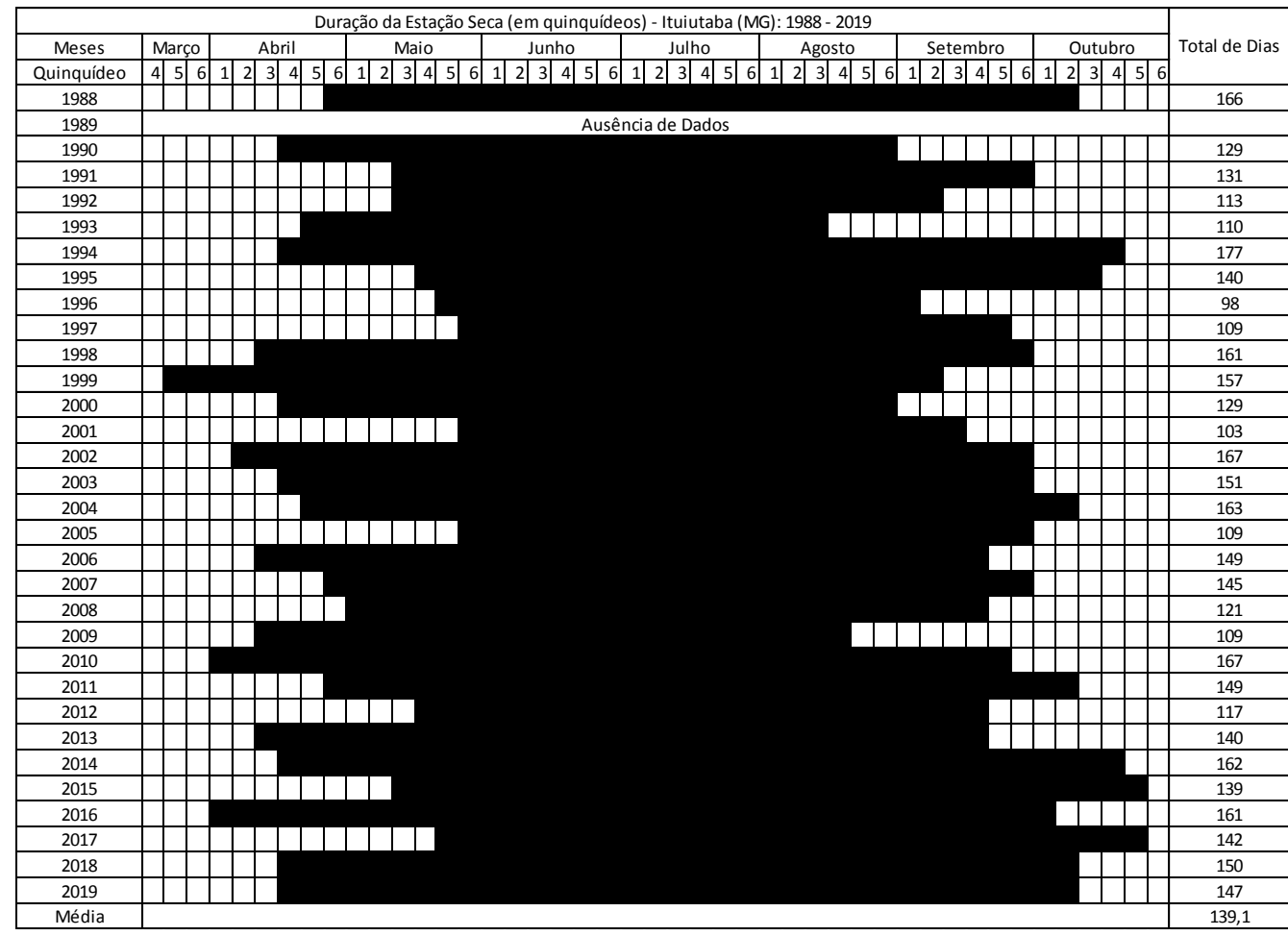

Gráfico 6 - Ituiutaba - MG: Início e término da Estação Seca (em quinquideos). Fonte de dados: Instituto Nacional de Meteorologia - INMET. Org: Costa e Queiroz, 2020

A estação chuvosa em $46,8 \%$ dos casos teve início no mês de setembro, mais especificamente, na segunda quinzena. O mês de outubro foi protagonista em $31,2 \%$ dos anos parainício da estação chuvosa.

O início da estação chuvosa é de grande relevância para a agricultura, pois define quando começa o plantio da safra, sobretudo, das lavouras temporárias. Portanto, o adiantamento ou retardamento do plantio está vinculado as chuvas que provocam o fim da estação seca.

Nota-se, portanto, que o processo de uso das águas superficiais e subterrâneas do município de Ituiutaba para a irrigação é de suma importância para o desenvolvimento da agricultura e pecuária. Vale salientar que, devido a tendencia de diminuição das chuvas, as águas subterrâneas estão sendo utilizadas de forma descontrolada. Pois de acordo com o estudo feito temos uma média de 139,1 dias sem chuva, sendo a economia municipal muito prejudicada sem um planejamento adequado.

\section{CONSIDERAÇÕES FINAIS}

Este estudo evidenciou a análise das precipitações no município de Ituiutaba - MG (série histórica 1988 a 2019), no intuito de definir o início e o final da estação seca e chuvosa e sua influência no processo de produção da agricultura do município. Os resultados apresentados indicam, que devido à sazonalidade do clima regional, possuímos uma estação seca que varia entre 98 dias (1996) a 177 dias (1994), caracterizando um período seco relativamente grande e que afeta o desenvolvimento da agricultura. 
Em relação aos dias sem precipitação, é notório afirmar que a cada década tem-se a tendência de aumento desses dias (6,5\% em cada década), isso evidencia a necessidade de se ter um planejamento mais elaborado a médio e longo prazos sobre a produção agrícola municipal, podendo minimizar osprejuízos econômicos e mitigar os impactos ambientais provenientes do uso intensivo da terra e da água.

Complementado as informações sobre tendências relacionadas a precipitação, destaca-se, ainda, a tendência observada de redução da precipitação anual ao longo da série histórica. Esse processo pode afetar diretamente o caminho e o ritmo da agricultura no município, seja na produção, semeadura ou no processo de irrigação, pois os cursos d'água serão extremamente afetados com essa diminuição.

Portanto, deve-se ficar atento para melhorias no que tange ao planejamento agrícola, principalmente adotando um calendário agrícola mais condizente com a realidade municipal, dando ênfase nos principais cultivares. Essa preocupação com o planejamento tem que ser de todos, produtores rurais, profissionais ligados ao setor agrícola, secretarias de agricultura e órgãos financiadores, principalmente em relação às mudanças climáticas que já é uma realidade no mundo.

\section{REFERÊNCIAS}

ASSUNÇÃO, W, L. Metodologia para Definição da Duração das Estações Seca e Chuvosa na Região dos Cerrados do Brasil Central. $1^{\circ}$ Encontro de Geógrafos da América Latina, Peru, p. 324 - 337, 2012.

AYOADE, J.O. Introdução a Climatologia para os trópicos. Tradução de Maria Juraci Zani dos Santos, revisão de Suely Bastos; coordenação editorial de AntonioChristofoletti. 14a Edição: Rio de Janeiro, 2003.

BRUNINI, O. et. al. Efeito dos elementos climáticos no desenvolvimento da cultura do milho. In: SIMPÓSIO SOBRE PRODUTIVIDADE DO MILHO. Londrina, 1983 Anais... Londrina: IAPAR, 1983, p. 21-39.

BACCARO, C. A. D. Unidades geomorfológicas do Triângulo Mineiro - Estudo Preliminar. Sociedade e Natureza, Uberlândia, v. 3, no 5 e 6, p. $37-42$, jan/dez. 1991.

COSTA, R. A. Riscos Ambientais em Cidades Pequenas do Cerrado Brasileiro. In: SEABRA, G. F. (Org.). Educação Ambiental no Mundo Globalizado: Uma ecologia de riscos, desafios e resistências. João Pessoa: EdUFPB, 2011. p. 199-214.

DINIZ, A. F. Variabilidade climática e sua influência na produtividade do milho na microrregião de Feira de Santana (Bahia). Dissertação de Mestrado. USP São Paulo, 2016.

Instituto Brasileiro de Geografia e Estatística (IBGE). Disponível em: https://www.ibge.gov.br/. Acesso em: 03 maio 2020.

MENDES, P. C; QUEIROZ, A. T. Caracterização climática do município de Ituiutaba-MG. In_PORTUGUÊS, A. P.; MOURA, G.; COSTA, R. A. (Org.) Geografia do Brasil central. Uberlândia: Assis, 2011, p. 333-353. 
MINAS GERAIS. INSTITUTO MINEIRO DE AGROPECUÁRIA (IMA). Vazio sanitário. Disponível em: http://www.ima.mg.gov.br/sanidade-vegetal/vazio-sanitario. Acesso em: 03 maio 2020.

MACHADO, M.A.M.; SEDIYAMA, G.C.; COSTA, J.M.N.; COSTA, M.H. Duração daestação chuvosa em função das datas de início do período chuvoso para o estado de MinasGerais. Revista Brasileira de Agrometeorologia, Santa Maria, v. 4, n. 2, p. 73-79, 1996.

MAIA, D. C e SANTOS, M. J. Z. Variabilidade Climática e sua Influência na Produtividade do Milho na Região de Pindamonhangaba (SP). Lúcia Helena de O. Gerardi e Magda Adelaide Lombardo (org.) Sociedade e Natureza na visão da Geografia. Rio Claro, 2003.

NAGHETTINI, Mauro; PINTO, Éber José de Andrade. Hidrologia estatística. Belo Horizonte: CPRM, 2007. 552 p.

NERY, J. T.; VARGAS, W.M.; MARTINS, M.L.O. Caracterização da precipitação no estado do Paraná. Revista Brasileira de Agrometeorologia, Santa Maria, v. 4, n. 2, p. 81-89, 1996.

Pereira, A. R.; Angelocci, L. R.; Sentelhas, P. C. Agrometeorologia: Fundamentos e aplicações práticas. Guaíba: Agropecuária, 2002. 478p.

QUEIROZ A. T.; COSTA, R. A. Caracterização e Variabilidade Climática em Séries de Temperatura, Umidade Relativa do Ar e Precipitação em Ituiutaba - MG. Revista Caminhos de Geografia. Uberlândia v. 13, n. 43 out/2012 p. 346-357

ROLDÃO, A. ASSUNÇÃO, W. L. Caracterização e Duração das Estações Seca e Chuvosa no Triângulo Mineiro/MG. REVISTA GEONORTE, Edição Especial 2, V.1, N.5, p.428 - 440, 2012.

ROLIM, G. S.; SENTELHAS, P. C. Balanço hídrico normal por Thorntwaite e Mather (1955). Piracicaba: ESALQ/USP - Departamento de Ciências Exatas: Área de Física e Meteorologia, 1999 (programa para Excel v. 6).

THORNTWAIRE, C. W.; MATHER, J. R. The water balance. Centertorn, N. J: Drexel Institute of Technology. 1955. 104p.

SCHNEIDER, H., \& SILVA, C. O Uso do Modelo Box Plot na Identificação de Anos-padrão Secos, Chuvosos e Habituais na Microrregião de Dourados, Mato Grosso do Sul. Revista Do Departamento De Geografia, GEOUSP 27, 131-146. 2014. 